thương sọ não, u não. Loại cơn động kinh thường gặp là động kinh toàn thể.

\section{TÀI LIÊU THAM KHẢO}

1. Dướng Huy Hoà̀ng (2009). Nghiên cứu một số đặc điểm dịch tể, lâm sàng động kinh, tình hình quản lý bệnh nhân động kinh tại tỉnh Thái Bình. Luân án Tiến sĩ Y học năm 2009.

2. Nguyê̂n Thúy Hường (2001). Nghiên cứu một số đặc điểm dịch tế và tình hình điêu trị động kinh tại cộng đồng tỉnh Hà Tây, Luận án Tiến sĩ Y học, Học viện Quân y.

3. Nguyến Vắn Hướng (2003). Dịch tễ động kinh tại xã Phù Linh, huyện Sóc Sơn, Hà Nội, Luận văn
Bác sĩ, Đai hoc Y Hà Nôii.

4. Ngố Tất Thà̀nh (2005). Nghiên cứu một số đăc điểm lâm sàng và cân lâm sàng của đông kinh khởi phát ở bệnh nhân tuổi từ 45 trở lên, Luận văn thạc sỹ $Y$ hoc, Học viện Quân y.

5. Nguyê̂n Anh Tuấn. (2007) "Tỷ lệ động kinh ở huyên $\mathrm{Ba}$ Vì.

6. Beghi E, Giussani G, Sander J W (2015). The natural history and prognosis of epilepsy. Epileptic Disord, 17 (3), 243-53.

7. Mohammad Q D, Saha N C (2020). Prevalence of epilepsy in Bangladesh: Results from a national household survey". 5 (4), 526-536.

\title{
MộT SỐ THUÂN LỢI, KHÓ KHĂN TRONG THU, CHI TÀI CHÍNH BÊ̂NH VIỆN ĐA KHOA TỈNH ĐẮK NÔNG GIAI ĐOẠN 2018- 2020
}

\section{TÓM TẮT}

Mục tiêu: Nghiên cứu phân tích một số yếu tố thuận lợi, khó khăn trong thu, chi tài chính Bệnh viện đa khoa tỉnh Đắk Nông giai đoạn 2018- 2020. Phương pháp nghiên cứu: Thiết kế nghiên cứu định tính sử dụng kỹ thuật phỏng vấn sâu và thảo luận nhóm với đại diện ban giám đốc bệnh viện, lãnh đạo phòng/ban chức năng, cán bộ y tế tại Bệnh viện đả khoa tỉnh Đắk Nông. Kết quả và kết luận: Các yếu tố thuân lợi gồmquy đinh về tư chủ tài chính của bệnh viện; Hoàn thiện các quy định, quy chế chi tiêu tài chính của bệnh viện; Quản lý, lãnh đạo của bệnh viện; Ứng dụng công nghể thông tin. Các yếu tố khó khăn gồm cần đối các nguồn thu chi của bệnh viện; Thiếu các văn bản hướng dẫn chi tiết, đồng bộ liên quan đến tài chính bệnh viện; Nhân lực còn thiếu về cả số lượng và chất lượng; Xuất toán BHYT; Tác động của bênh dich COVID-19.

Tứ khóa: tài chính bệnh viện, thuận lợi, khó khăn, Bệnh viện đa khoa tỉnh Đắk Nông.

\section{SUMMARY \\ SOME FAVORABLE AND UNFAVORABLE \\ FACTORS IN FINANCIAL REVENUE AND EXPENDITURE AT DAK NONG PROVINCIAL GENERAL HOSPITAL, 2018 - 2020}

Objective: To study several favorable and unfavorable factors in financial revenue and expenditure of Dak Nong Provincial General Hospital in the period of 2018-2020. Research Methods: Design a qualitative study using in-depth interview techniques and focus group discussions with representatives of

${ }^{1}$ Trường Đại Học Y tế Công Cộng,

2Bênh viên đa khoa tỉnh Đắk Nông

Chịu trách nhiệm chính: Nguyễn Quỳnh Anh

Email: nqa@huph.edu.vn

Ngày nhận bài: 10.9.2021

Ngày phản biên khoa hoc: 29.10.2021

Ngày duyệt bài: 12.11.2021

\section{Nguyễn Quỳnh Anh"1, Trần Thanh Bình ${ }^{2}$}

the hospital's board of directors, leaders of functional departments/departments, medical staff at Dak Nong Provincial General Hospital. Results and conclusions: Favorable factors include regulations on financial autonomy of hospitals; Completing the hospital's financial spending regulations and regulations; Management and leadership of the hospital; Information technology applications. Unfavorable factors include balancing the hospital's revenues and expenditures; Lack of detailed and synchronous guiding documents related to hospital finance; Human resources are lacking in both quantity and quality; Export health insurance payment; Impact of the COVID-19 pandemic.

Keywords: hospital finance, favorable factors, unfavorable factors, Dak Nong Provincial General Hospital.

\section{I. ĐĂT VẤN ĐỀ̂}

Tài chính bệnh viện (TCBV) giữ vai trò vô cùng quan trọng đối với hoạt động của bệnh viện. Sau hớn 10 năm thực thi Nghị định 43/2006/NĐ-CP, hoạt động của các đơn vị sự nghiệp công lập trên thực tế đã phát sinh nhiêu vấn đề chưa phù hợp với tinh thân của Nghị định [1]. Nhằm hạn chế các bất cập của Nghị định 43/2006/NĐ-CP, Chính phủ đã ban hành Nghi định 16/2015/NĐ-CP để đáp ứng nhu câu đổi mới, phát triển hoạt động sự nghiệp [2]. Tiếp đó, Bộ Y tế bắt đầu thực hiện Chiến lược tài chính y tế giai đoạn 2016 - 2025, đưa ra một số giải pháp chung để hướng đến hệ thống y tế bền vững hơn [3]. Bệnh viện đa khoa tỉnh Đắk Nông là bệnh viện hạng II trực thuộc Sở Y tế tỉnh Đắk Nông. Trong những năm gân đây công tác khám chữa bệnh được duy trì thường xuyên, chất lượng điêu trị và phục vụ từng bước được cải thiện đáng kể, cơ bản đáp ứng nhu câu chăm sóc sức khỏe cho nhân dân trong tỉnh. Bệnh viện 
bắt đầu chuyển sang cơ chế tự chủ về tài chính - tự đảm bảo một phần chi thường xuyên từ năm 2016. Tuy nhiên trong quá trình hoạt động vẫn còn một số khó khăn bất cập trong việc quản lý và tự chủ về tài chính của bệnh viện, chưa có hiệu quả để thu hút nguồn bệnh nhân đến khám cũng như thu hút được nguồn cán bộ yên tâm công tác tại bệnh viện. Đây là một bài toán khó mà Bệnh viện đa khoa tỉnh Đắk Nông gặp phải. Với nhu cầu cân thiết hiện nay bệnh viện cần tìm hiểu các khó khăn, thuận lợi để đảm bảo các hoạt động và phát triển Bệnh viện. Vì vậy chúng tổi tiến hành nghiên cứu "Một số thuận lợi, khó khăn trong thu, chi tài chính Bệnh viện đa khoa tỉnh Đắk Nông giai đoạn 2018-2020".

\section{II. ĐỐI TƯƠNG VÀ PHƯƠNG PHÁP NGHIÊN CỨU}

Thiết kế nghiên cứu: Nghiên cứu định tínhbao gồm thảo luận nhóm và phỏng vấn sâu.

Đối tượng nghiên cứu:Lãnh đạo Bệnh viên, lãnh đạo phòng/ ban chức năngvà các CBYT trong bệnh viện.

Thời gian và địa điểm nghiên cứu: Nghiên cứu được thực hiện từ tháng 02/2021 đến tháng 09/2021 tại bệnh viện Đa khoa tỉnh Đắk Nông.

Phương pháp thu thập số liệu: Sử dụng hướng dẫn phỏng vấn sâu (PVS) để PVS 05 đối tượng bao gồm 01 lãnh đạo bệnh viện và 06 lãnh đạo phòng/ ban chức năng (phòng Tổ chức \& Hành chính, phòng Kế hoạch tổng hợp và Vật tư trang thiết bị, phòng Tài chính - Kế toán) và 01 cán bô phòng Tài chính - Kế toán và sử dụng hướng dẩn thảo luận nhóm (TLN) để thực hiện 01 cuộc TLN với các người cung cấp dịch vụ y tế (Bác sỹ phụ trách chuyên môn và Điều dưỡng, số lượng 8-10 người.

\section{Chủ đề nghiên cứu định tính:}

- Tìm hiểu các yếu tố thuận lợi: Quy định về tự chủ tài chính của bệnh viện. Hoàn thiện các quy định, quy chế chi tiêu tài chính của bệnh viện. Quản lý, lãnh đạo của bệnh viện. Ứng dụng công nghê thông tin.

- Tìm hiểu các yếu tố khó khăn: Cân đối các nguồn thu chi của bệnh viện. Thiếu các văn bản hướng dẫn chi tiết, đồng bộ liên quan đến tài chính BV.Nhân lực còn thiếu về cả số lượng và chất lượng. Xuất toán BHYT. Tác động của bệnh dịch COVID-19.

Phương pháp phân tích số liệu: Sắp xếp các bản ghi chép và băng phỏng vẩn sâu. Tiến hành gõ băng, mã hóa theo chủ đề và trích dẫn theo mục tiêu nghiên cứu.

Đạo đức nghiên cứu: Nghiên cứu được tiến hành sau khi Hội đồng Đạo đức Nghiên cứu Y
Sinh học trường Đại học $Y$ tế công cộng xem xét và phê duyệt thông qua theo công văn số 253/2021/YTCC-HD3 ngày 25/05/2021.

\section{KẾT QUẢ NGHIÊN CỨU}

Một số thuận lợi của bênh viên trong hoạt động thu, chi tài chính. Quy định về tự chủ tài chính của bệnh viện. Năm 2019, BVĐK tỉnh Đắk Nông thực hiện lộ trình tự chủ theo Quyết định số 1473/QĐं-UBND của UBND tỉnh Đắk Nông giai đoạn 2019-2021. Dưới tác động thực hiện tự chủ, cơ cấu các nguồn thu chính của bệnh viện có nhiều biến động. Ngân sách nhà nước cấp giảm nhiều qua các năm và thay vào đó tăng nguồn thu sự nghiệp.

"...thay đổi cơ cấu các nguồn thu là thay đổi cơ chế về chính sách về tài chính để thực hiện tự chủ, sự đầu tư từ ngân sách nhà nước giảm dần và tiến đễn các đơn vị tự chủ toàn bộ về tài chính. Riêng đối với BVĐK tỉnh Đắk Nồng với xuất phát điểm thấp và tác động đại dịch COVID-19 nên việc thực hiện tự chủ là khó khăn và gặp nhiều thách thức..." (TLN)

Hoàn thành các quy định, quy chế liên quan đến tài chính bệnh viện. Thông qua Hội nghị CCVC, bệnh viên xây dựng quy chế chi tiêu nội bộ nhẳm quản lý, sử dụng nguồn kinh phí hiệu quả, đúng mục đích và phù hợp với thực tế đơn vị, giảm thiếu tối đa thất thoát chi phí không hợp lý.

"...hoạt động Ban thanh tra nhân dân và giúp cho Lãnh đạo và nhân viên thực hiện chi phí hợp lý và tiết kiệm, trách được các hiện tượng tiêu cực trong sử dụng tài chính đơn vị, trong Hội nghị này điều chỉnh các mục chi hợp lý, thực hành tiết kiệm để tăng thu nhập cho nhân viên " (PVS-03)

Quản lý, lãnh đạo của bệnh viện. Phòng Tài chính - Kế toán có tầm quan trọng tham mưu lãnh đạo việc thu chi sao cho hợp lý và hiệu quả. Năng lực lãnh đạo phòng và nhân viên phải được nâng cao qua các lớp đào tạo, tập huấn liên tục để đáp ứng được cơ chế thay đổi tài chính hiện nay. Theo kết quả phỏng vấn sâu "....ãnh đạo bệnh viện cần tư duy về quản lý tài chính và nhạy bén với thay đổi cơ chế chính sách và quản lý tốt bộ phận tài chính đơn vị, biết lắng nghe và học hỏi kinh nghiệm quản lý các bệnh viện khác có hiệu quả để định hướng theo..." (PVS-04)

Ứng dụng công nghệ thông tin. BVĐK tỉnh Đắk Nông từ năm 2014 cài đặt, phần mềm quản lý khám, chữa bệnh chung của bệnh viện. Phần mềm quản lý chung của bệnh viện đã được quản lý, giám sát tất cả những thuốc, vật tư tiêu hao, những dịch vụ kỹ thuật. Phòng Tài chính - Kế 
toán thì có phần mềm Misa để quản lý lĩnh vực tài chính kế toán.

Một số khó khăn của bệnh viện trong hoạt động thu, chi tài chính. Cân đối các nguồn thu bệnh viện thực hiện tự chủ tài chính. BVĐK tỉnh Đắk Nông gặp khó khăn khi bắt đầu tự chủ một phần theo Nghị định 85/NĐ-CP thực hiện tự chủ toàn bộ nhóm 2, với xuất phát điểm thấpvà ảnh hưởng đại dịch COVID-19 nên việc cân đối nguồn thu liên quan đến hoạt động bênh viện giảm trầm trọng. Khi thực hiện Nghị định 43/NĐ-CP nghĩa là bệnh viện được trao quyên tự chủ, trong khi đó nếu bệnh viện đã đạt trên 95\% thì kinh phí vẫn không được tự chủ về biên chế.

Thiếu các văn bản hướng dẫn chi tiết, đồng bộ liên quan đến tài chính bệnh viện. Đa số các bệnh viện công vẫn đang được phân bổ ngân sách trên cơ sở những mục ngân sách theo yêu cầu nguồn lực đầu vào (số giường bệnh, hợp đồng lao đồng 68). Tuy theo Thông tư 08 /TTLB -BVN-BYT năm 2007 hướng dẫn định mức biên chế sự nghiệp trong các cơ sở y tế nhà nước. Nhưng khi giao biên chế Bộ Nội vụ chưa cấp đủ biên chế theo thông tư cho các cơ sở y tế và hàng năm tỉnh giản biên chế từ $5-10 \%$, trong khi đó $\mathrm{BHXH}$ quy định số lượt khám chữa bệnh trong ngày/ CBYT, quá số lượng bệnh nhân đến khám/ CBYT/ngày không được thanh toán.Về cơ bản, ngân sách theo định hướng đầu vào nhằm mục tiêu kiểm soát chi tiêu mà không gắn ngân sách với chất lượng, hiệu quả công việc và kết quả đầu ra. Viêc "hoàn thành kế hoach" luôn đi kèm với việc "giải ngân" phần ngân sách đã được phân bổ mà không có những yếu tố khuyển khích sử dụng nguồn lực một cách hiệu quả.

Khi thực hiện tự chủ bệnh viện, kinh phí hoạt động phụ thuộc vào nguồn thu khám chữa bệnh, nhưng các quy định thanh toán, quyết toán BHXH phức tạp, chậm trễ trong việc chi trả cho bệnh viện. Qua phỏng vấn sâu cho thấy "...giao quỹ bảo hiểm năm sau không cao hơn năm trước, trong khi áp dụng thanh toán thực thanh thực chi, khi vượt quỹ giải trình rất vấn vả và còn bị treo, thanh toán không kịp thời... " (PVS-01)

Nhân lực y tế còn thiếu về số lượng và chất lương. Theo kết quả phỏng vấn sâu "...nhân lực các khoa cận lâm sàng, phòng khám, HCSS thiểu, nên động viên nhân viên y tế làm thêm giờ, nhiều khi phải điều động bác sỹ chưa được đào tạo chuyên sâu đến hổ trợ khoa thiếu nhân lực... cơ quan chi trả lương ngoài giờ cao, và chất lượng khám chữa bệnh có ảnh hưởng..." (PVS-01)

Nhận thức về tự chủ một số bộ phận nhân viên y tế còn hạn chế, phần nào cũng ảnh hưởng đến cải tiến chất lượng bệnh viện, triển khai các dịch vụ kỹ thuật, tinh thần thái độ phục vụ người bệnh đã liên quan đến nguồn thu đơn vị. Vẫn còn có tư duy và tư tưởng ỷ lại vào bao cấp nhà nước, chưa thay đổi tác phong lề lối làm việc, chậm đổi mới. Trong năm 2020, mức thu nhập tăng thêm cho nhân viên y tế hầu như không có, đơn vị chỉ cố gắng chi trả lương và phụ cấp cho nhân viên.

Xuất toán bảo hiểm y tế. Qua phỏng vấn sâu cho thấy "...xuất toán BHXH đã ảnh hưởng đến nguồn thu đơn vị, đơn vị cũng đã giải trình liên quan do văn bản hướng dẫn chồng chéo giữa BYT và $\mathrm{BHXH}$ như: số cán bộ khám/ phòng, khoa /ngày, các thủ tục hành chính liên quan bệnh nhân như: thông tin thẻ, mã số, thẻ hết hạn..." (TLN).

Bệnh viện gặp khó khăn định mức thanh toán BHYT liên quan máy móc TTBYT và nhân viên y tế thực hiện dịch vụ. Trong khi đó, các văn bản hướng dẫn các bộ liên quan chồng chéo, không cụ thể, chỉ quy chuẩn để thanh toán, nhiều lúc giải quyết mang cảm tính, không khách quan...

"...việc từ chối thanh toán BHYT liên quan đến định mức, văn bản hướng dẫn không cụ thể. Bệnh viện cũng đã có nhiêu văn bản kiện nghị SYT, BHXH và UBND tỉnh qua các đợt thanh tra. Tuy nhiên các đơn vị liên quan trả lời đang làm văn bản xin ý kiến của cấp trên và đây cũng là một trong những khó khăn, của tất cả các cơ sở y tế chứ không riêng một mình BVĐK tỉnh Đắk Nông..." (PVS-03)

Tác động bệnh dịch COVID-19. Tác động của dịch bệnh COVID-19 đã ảnh hưởng trầm trọng đến số lượng người đến khám, chữa bệnh, công suất hoạt động triển khai dịch vụ y tế giảm mạnh.Ngoài ra còn ảnh hưởng xâu đến nguồn thu của bệnh viện liên quan chi trả lương và phụ cấp nhân viên y tế. Theo kết quả thảo luận nhóm "...hiện nay, báo cáo 6 tháng đầu năm của bệnh viện, đơn vị thu được khoảng gần $37 \%$. Tuy nhiển, đánh giá về 6 tháng cuối năm thì tỷ lệ thu giảm rất nhiều, đặc biệt là thu dịch vụ có thể giảm tới $50 \%$ và thu sự nghiệp có thể giảm đến khoảng $20-25 \%$. Ngoài ra, riêng nguồn thu từ nhà xe giảm rất nhiều từ việc thu sự nghiệp, thu viện phí BHYT cũng giảm rất lớn. Vì do bệnh viện thực hiện áp dụng chỉ thị 15 và chỉ thị 16 nển bệnh nhần cũng ngại đến với các cơ sở y tế, nguồn thu giảm mạnh ... bệnh viện luôn cố gắng đảm bảo chi lương của nhân viên ổn định đồng thời phải chi thêm những đồ dùng để chuẩn bị cho công tác phòng chống dịch. Như vậy, nguồn thu đã ít mà vẫn phải chi ra nhiều hơn..." (TLN) 


\section{BÀN LUÂN}

Một số thuận lợi của bệnh viện trong hoạt động thu, chi tài chính. Việc thực hiện tự chủ tại các đơn vị sự nghiệp có thu trong ngành y tế những năm gần đây là một biện pháp quan trọng trong quá trình phân cấp quản lý nói chung và phân cấp về quản lý tài chính $Y$ tế nói riêng. Kết quả khảo sát từ tổng quan $Y$ tế năm 2012 cho thây, các bệnh viện tuyến Trung ương, tuyến tỉnh/thành phố có mức tự chủ mạnh hơn rất nhiều so với các bệnh viện tuyến huyện [4]. Trong nghiên cứu này cho thấy, mức độ tự chủ của Bệnh viện trong việc không tăng cung cấp các kỹ thuật mới và nguồn thu không tăng lên đáng kể. Tuy nhiên, việc đánh giá mức độ tự chủ của Bệnh viện hiện nay mới chỉ dựa vào một phần kết quả thu - chi mà chưa có tiêu chí cụ thể, rõ ràng để đánh giá.

Nhằm quản lý, sử dụng các nguồn thu bệnh viện xây dựng và ban hành quy chế chi tiêu nội bộ để quản lý, sử dụng nguồn kinh phí hiệu quả, đúng mục đích và phù hợp với thực tế đơn vị, giảm thiếu tối đa thất thoát chi phí không hợp lý. Song song với thực hiện quy chế chi tiêu nội bộ đã tao động lực cho đội ngũ nhân viên y tế phục vụ và cống hiến. Bệnh viện áp dụng khen thưởng kịp thời, tuyên dương nhiều gương điển hình tiên tiến trong tinh thần trách nhiệm và tận tụy chăm sóc bênh nhân.

Năng lực quản lý của người lãnh đạo là yếu tố quyết định đến sự phát triển đơn vị bất cử tổ chức đớn vị nào. Riêng BVĐK tỉnh Đắk Nông với xuất phát điểm thấp về nguồn lực và trong một thời gian ngắn mà thay đổi nhiều lần người đứng đầu bênh viên sẽ có ảnh hưởng đến sự phát triển bệnh viện, chắc có lẽ chỉ BVĐK tỉnh Đăk Nông là còn bệnh viện tuyến tỉnh công lập phân hạng II. Trong nghiển cứu của Trịnh Đăng Anh tại bệnh viện Y học cổ truyển tỉnh Đăk Lăk cho thây lãnh đạo đương nhiệm bệnh viên được đánh giá có tư duy, năng lực quản lý tốt và khả năng định hướng bệnh viện phát triển [5]. Đây được xem như một trong những thuận lợi của bệnh viện trong thực hiện lộ trình tự chủ.

Giai đoạn 2015-2016, BVĐĐ tỉnh Đắk Nông đã đầu tư kinh phí để phát triển và nâng cao chất lượng CNTT của bệnh viện. Cài đặt, phân mềm quản lý khám, chữa bệnh chung của bệnh viện và phần mềm Misa để quản lý lĩnh vực tài chính kễ toán. Việc ứng dụng công nghệ thông tin đã giúp cho bênh viện thuận lợi trong công tác quản lý tổng thể và công tác khám chữa bệnh, nhất là khám chữa bệnh BHYT. Đối với công tác liên quan đến tài chính kễ toán, bệnh viện cũng đã sử dụng các phần mềm hỗ trợ... góp phần cải thiện hiệu suất làm việc cũng như khả năng quản lý, kiểm soát tài chính tại đơn vị, nhất là làm giảm tỷ lệ thất thu viện phí.

Một số khó khăn của bệnh viện trong hoạt động thu, chi tài chính. Việc thiếu các quy định, hướng dẫn rõ ràng dẫn đến quá trình vừa làm, vừa tìm tòi, nghiên cứu trong giai đoạn bệnh viện mới thực hiện tự chủ. Điều này cũng tương đồng với kết quả nghiên cứu của Ninh Tiên Hoàng được thực hiện năm 2013 tại bệnh viện đa khoa huyện Cư Kuin và Krông Ana thuộc tỉnh ĐắkLắk giai đoạn 2010-2012, chỉ rõ việc thiếu các hướng dẫn và các quy định cụ thể về triển khai, giám sát đã phần nào ảnh hưởng đến hoạt động chuyên môn của bệnh viện [6].

Theo Thông tư 08/TTLB - BNV - BYT, bệnh viện thiếu nhân lực và hàng năm còn tinh giản từ $5-10 \%$ (bệnh viện còn thiếu gần 100 biên chế) đã ảnh đển công tác đào tạo, triển khai dịch vụ kỹ thuật theo ê kíp, cơ cấu theo các bộ phận lâm sàng, cận lâm sàng và quản lý - hành chính không hợp lý làm ảnh hưởng đến định hướng phát triển bệnh viện. Nhận thức về tự chủ một số bộ phận nhân viên y tế còn hạn chế, phần nào cũng ảnh hưởng đến cải tiên chất lượng bệnh viện, triển khai các dịch vụ kỹ thuật, tinh thần thái độ phụ vụ người bệnh... đã liên quan đến nguồn thu đơn vị. Trong năm 2020, mức thu nhập tăng thêm cho nhân viên y tế hầu như khổng có, đơn vị chỉ cố gắng chi trả lương và phụ cấp cho nhân viên, có phần nào ảnh hưởng đến động cơ làm việc, triển khai dịch vụ kỹ thuât tại đơn vị và hiện tượng chảy máu chất xám vẫn tiếp diễn tại đơn vị...

Hiện nay, dữ liệu trên hêe thống phần mềm giám đinh BHYT chưa liên thông lịch sử khám chữa bểnh của người bênh ngay từ đầu vào viện khám, chữa bệnh mà phải kết thúc đợt khảm, điều trị ngoại trú hoặc nội trú mới liên thông trên hệ thống, vì vậy vẫn còn tình trạng người bệnh khi vào viện khám, điều trị đã được tra cứu đầy đủ lịch sử khám bệnh, chữa bệnh và kiểm tra các thủ tục hành chính theo quy định, tuy nhiên sau khi bệnh nhân ra viện mới phát hiện trùng thời gian điều trị với các cơ sở y tễ khác. Các nguyên nhân được chỉ ra tại BVĐK tỉnh Đắk Nông gồm: Nguyên nhân khách quan do chế độ, chính sách hoăc NVYT chưa hiểu về những thay đổi cơ cấu thanh toán hoặc cách thanh toán. Nguyên nhân chủ quan là chưa thống nhất giữa hai bên, bệnh viện thao tác làm đúng nhưng bảo hiểm báo làm sai nên bi ảnh hưởng nhiều, bị xuất toán các mục bị từ chối thanh toán. 
Theo Tổng giám đốc WHO, Ông Tedros Adhanom Ghebreyesus cho rằng " Đại dịch này là một cuộc khủng hoảng y tế một trăm năm nay mới xảy ra một lần, những tác động của nó sẽ còn kéo dài nhiều thập kỷ nữa". Chính vì vậy, trên thế giới, sau "cú sốc choáng váng ban đầu, các nước đã áp dụng một loạn giải pháp " phi y tế " để ngăn chặn sự lầy lan của đại dịch giữa các nước, giữa các vùng, khu vực, đơn vị, gia đình, người với người. Những thay đổi này rất cần thiết để ứng phó với đại dịch COVID-19 nhưng đe dọa đến khả năng tài chính của các Bệnh viện, đặc biệt là những Bệnh viện đang gặp khó khăn trong vấn đề tài chính và những Bệnh viện phụ thuộc nhiều vào hoạt động khám chữa bệnh ngoại trú [7]

\section{KẾT LUẬN VÀ KHUYẾN NGH!}

Cần sớm sửa đổi, bổ sung các văn bản hướng dẫn về thực hiện tự chủ, tự chịu trách nhiệm của đơn vị sự nghiệp y tế công lập theo hướng tạo điều kiện thuận lợi cho các đớn vị cấp dưới, cụ thể là có hướng dẫn phù hợp với việc trích lập và sử dụng quỹ cải cách tiền lương. Kiện toàn quy trình, thủ tục giám định, thanh quyết toán BHYT cho các cơ sở y tế công lập. Định mức biên chế trong giai đoạn thực hiện lộ trình tự chủ.

\section{TÀI LIẸU THAM KHẢO}

1. Chính phủ (2006), Nghi định số $43 / 2006 / N D-C P$, ngày 25/4/2006 của Chính phủ quy định quyền tứ chủ, tự chịu trách nhiệm và thực hiện nhiệm vụ, tổ chức bộ máy, biên chế và tài chính đối với đớn vị sự nghiệp công lập, chủ biên.

2. Chính phủ (2015), Nghị định số 16/2015/ND-CP của Chính phủ : Quy định cơ chế tự chủ của đơn vị nghiệp công lập,

3. Vư hợp tác quốc tế, Bộ Y tế (2017). Chiến lược Tài chính Y tế Việt Nam giai đoạn 20162025.http://icdmoh.gov.vn/tin-tuc/chien-luoc-taichinh-y-te-viet-nam-giai-doan-20162025.html.

4. Bộ Y tế, World Health Organization (2010), Tài khoản y tế quốc gia thực hiện ở Việt Nam thới kỳ 1998-2008, Nhà Xuất bản Y học, Hà Nội.

5. Trịnh Đăng Anh (2019), Thực hiện thu chi tài chính và một số thuâan lợi khó khăn tại Bệnh viện Y học cổ truyền tỉnh Đ̇ắk Lắk giai đoạn 2016-2018, Luận văn CKII - Tổ chức quản lý y tế. Trường Đại học Y tế công cộng, Hà Nội.

6. Ninh Tiên Hoàng (2013), Thực trang hoạt động tài chính tại bênh viện đa khoa huyện Cư Kuin và Krông Ana thuộc tỉnh ĐắkLắk giai đoạn 2010-1012, Luận văn Thạc sỹ Quản lý bệnh viện. Trường Đại học Y tế Công cộng, Hà Nội.

7. Webb, E., Hernandez-Quevedo, C., Scarpetti, G., et al. (2020). Restarting more routine hospital activities during COVID-19: approaches from six countries. Eurohealth, 26(2), 68-73.

\section{KẾT QUẢ ĐIỀU TRI VIÊM PHỔI VÀ NHIỄM KHUẨN HUYẾT DO KLEBSIELLA PNEUMONIAE SỬ DUUNG AMIKACIN CÓ GIÁM SÁT NỒNG Độ TRONG MÁU}

\section{TÓM TẮT}

Mục tiêu: Đánh giá kết quả điều tri viêm phổi và nhiễm khuẩn huyết do Klebsiella.pneumoniae sử dụng amikacin có giám sát nồng độ trong máu và mô tả độc tính trên thận. Đối tượng và phương pháp nghiên cứư: Nghiên cứu lâm sàng can thiệp trên bệnh nhân nhiễm khuẩn huyết hoăc viêm phổi do K.pneumoniae tại khoa Hồi sức tích cực. Liều amikacin là $30 \mathrm{mg} / \mathrm{kg}$ cần nặng hiệu chỉnh (ABW). Mục tiêu giám sát nông độ thuốc trong máu (TDM) là $\mathrm{C}_{\text {peak }}$ : $45-60 \mathrm{mg} / \mathrm{L}$, $C_{\text {peak }} / \mathrm{MIC}: 8-10, \mathrm{C}_{\text {trough }}<2 \mathrm{mg} / \mathrm{L}$. Chúng tôi ghi nhân đáp ứng lâm sàng và sự phát triển tổn thương thận cấp. Kết quả: 42 bênh nhân được nhận vào nghiền cứu, có tuổi trung bình $56,1 \pm 19$. Nam giới chiếm $76,2 \%$. Điểm APACHE II 16, điểm SOFA ngày vào

* Trường Đại học y Hà Nội

Chịu trách nhiệm chính: Phạm Thị Hồng Phương

Email: hongphuong98147@gmail.com

Ngày nhận bài: 9.9.2021

Ngày phản biên khoa hoc: 2.11.2021

Ngày duyệt bài: 10.11.2021

\section{Phạm Thị Hồng Phương*, Đặng Quốc Tuấn*}

khoa 8[4,5], điểm Chalson 1[2]. Tỉ lệ sốc nhiễm khuẩn tai thời điểm dùng amikacin $35,7 \%$. Bênh nhân thơ máy chiếm $85,7 \%$. Viêm phổi chiếm $83,3 \%$. MIC của K.pneumoniae với amikacin $4[2-5]$, tî lệ $\mathrm{MIC} \leq 8$ là $92,9 \%$. Tỉ lệ bệnh nhân đáp ứng lâm sàng hoàn toàn là $57,1 \%$. Tỉ lệ đáp ứng lâm sàng hoàn toàn ngày thứ 5 tăng hơn ngày thứ 3 , ngày thứ 7 tăng hơn ngày thứ $5(p<0,05)$. Nhóm đáp ứng lâm sàng hoàn toàn và nhóm không đáp ứng lâm sàng hoàn toàn có sự khác biêt về điểm APACHE II, điểm SOFA ngày vào khoa, điểm SOFA lúc bắt đầu điều trị, Hct lúc bắt đầu điều trị và tỉ lệ thở máy $(p<0,05)$, không có sự khác biệt về $\mathrm{C}_{\text {peak }} / \mathrm{MIC}$ và MIC ( $\left.\mathrm{p}>0,05\right)$. Trong những bệnh nhân $\mathrm{C}_{\text {trough }}<2 \mathrm{mg} / \mathrm{L}$ tỉ lệ xuất hiện tổn thương thận là 38,1\% và $87,5 \%$ ơ giai đoạn nguy cơ. Thời gian xuất hiện tổn

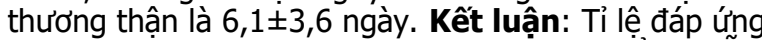
lâm sàng hoàn toàn khi điều tri viêm phổi, nhiễm khuẩn huyết do K.pneumoniae sử dụng amikacin liều $30 \mathrm{mg} / \mathrm{kg}$ ABW là 57,1\%. Bệnh nhân có điểm APACHE II cao, SOFA lúc vào khoa cao, SOFA lúc bắt đầu điều trị cao và bệnh nhân thở máy có đáp ứng lâm sàng kém hơn. Tỉ lệ tổn thương thận cấp ở các bệnh nhân nghiên cứu là $38,1 \%$. 